Clinical Toxicology

\title{
The metabolic effects of fatal cyanide poisoning
}

\author{
B.M. Singh, N. Coles, P. Lewis, R.A. Braithwaite', M. Nattrass and \\ M.G. FitzGerald
}

The General Hospital, Steelhouse Lane, Birmingham B4 6NH and ' Regional Laboratory for Toxicology, Dudley Road Hospital, Birmingham B18 7QH, UK.

\begin{abstract}
Summary: Metabolic and toxicological data were obtained during the first 24 hours following severe and eventually fatal cyanide poisoning. Initial blood cyanide concentrations were $804 \mu \mathrm{mol} / \mathrm{l}$ but fell rapidly over 24 hours following cobalt edetate therapy to $15 \mu \mathrm{mol} / \mathrm{l}$. However, plasma thiocyanate concentrations rose over 24 hours (147-267 $\mu \mathrm{mol} / \mathrm{l})$ suggesting continued tissue detoxification. The major metabolic abnormality was lactic acidosis (initial pH 7.21, blood lactate $17.5 \mathrm{mmol} / \mathrm{l}$ ) which corrected over 12 hours. Despite high circulating insulin concentrations the responses of blood glucose, plasma non-esterified fatty acid, blood glycerol and 3-hydroxybutyrate suggested marked insulin resistance.
\end{abstract}

Introduction

A case of fatal cyanide poisoning, previously reported, ${ }^{1}$ is described in which detailed toxicological and metabolic data were obtained. These metabolic sequelae are discussed.

\section{Case report}

A previously well 24 year old man was admitted as an emergency. The patient had been working alone in the bottom of a silver plating tank removing several inches of residue of silver cyanide sludge without protective clothing or respirator or supervision and was found unconscious in the sludge by his workmakes. An immediate antidote of amyl nitrite was not administered. The air in the tank was subsequently found to contain 200 parts per million of hydrogen cyanide.

On arrival in casualty his hair and clothes were matted with a black compound. He had chemical burns on exposed skin which had the characteristic brick red colour of cyanide poisoning. There was a strong odour of bitter almonds. He was apnoeic and his pulse was 120 beats per minute, faintly palpable but with no recordable blood pressure. His pupils were fixed and dilated and he was flaccid with no response to pain. He underwent immediate endotracheal

Correspondence: B.M. Singh, M.D., M.R.C.P., Department of Diabetes and Endocrinology, 9th Floor, Charing Cross Hospital, Fulham Palace Road, London W6 8RF, UK. Accepted: 27 June 1989 intubation and an intravenous infusion was established through which $300 \mathrm{mg}$ cobalt edetate together with $50 \mathrm{ml}$ of $50 \%$ dextrose was administered at 1 and 2 min after arrival. Subsequent to the second dose the patient began spontaneous breathing but lapsed into apnoea by 7 minutes when a third dose of antidote was administered with no effect upon respiration although facial oedema developed. Mechanical ventilation was initiated.

Blood investigations after the initial resuscitation period revealed a haemoglobin of $16.5 \mathrm{~g} / \mathrm{dl}$, a leucocytosis of $20.4 \times 10^{9}$ cells $/ 1$, sodium $145 \mathrm{mmol} / \mathrm{l}$, potassium $4.7 \mathrm{mmol} / 1$, urea $6.9 \mathrm{mmol} / \mathrm{l}$, glucose $18.7 \mathrm{mmol} / \mathrm{l}$ and arterial blood $\mathrm{pH} 7.08, \mathrm{PO}_{2} 68.5 \mathrm{kPa}$, $P_{C_{2}} 4.5 \mathrm{kPa}$ and $\mathrm{HCO}_{3} 10 \mathrm{mmol} / \mathrm{l}$ on $100 \%$ inspired oxygen. An electrocardiogram showed antero-lateral ischaemia.

His skin was washed. A naso-gastric tube was passed and gastric lavage performed. A flow directed catheter was inserted into the pulmonary artery to monitor colloid fluid replacement therapy. Despite adequate volume replacement he required inotropic support to maintain his systolic blood pressure at $100 \mathrm{mmHg}$. He was anuric for 4 hours but subsequently entered a gross polyuric phase lasting 24 hours. An insulin infusion of short-acting human insulin of 6 units/h and increased to 12 units/h at 12 hours was initiated. No further glucose was administered. Other investigations were performed during the first 24 hours of admission (Table I).

At 24 hours he was no longer acidotic and his blood pressure and urine output were stable but an electro-

(C) The Fellowship of Postgraduate Medicine, 1989 
Table I Toxicological and metabolic data obtained during the first $24 \mathrm{~h}$ following cyanide poisoning

\begin{tabular}{|c|c|c|c|c|c|c|c|}
\hline & \multicolumn{7}{|c|}{ Time from arrival $(h)$} \\
\hline & $1 / 2$ & 2 & 4 & 12 & 18 & 24 & Reference range* \\
\hline Blood cyanide $\mu \mathrm{mol} / \mathrm{l}$ & 804 & 819 & 608 & 23 & 15 & 15 & $(<2)$ \\
\hline Plasma thiocyanate $\mu \mathrm{mol} / 1$ & NA & 147 & 172 & 345 & 281 & 267 & $(10-70)$ \\
\hline Blood pH & 7.21 & 7.23 & 7.27 & 7.33 & 7.40 & 7.41 & $(7.38-7.46)$ \\
\hline Plasma insulin $\mathrm{mU} / \mathrm{l}$ & 36 & 17 & 46 & 54 & 120 & 56 & $(<1-4.1)$ \\
\hline Blood glucose $\mathrm{mmol} / \mathrm{l}$ & 23.6 & 21.4 & 22.6 & 44.5 & 13.6 & 17.1 & $(3.9-5.0)$ \\
\hline Blood lactate $\mathrm{mmol} / \mathrm{l}$ & 17.5 & 13.0 & 5.4 & 3.8 & 2.4 & 2.2 & $(0.5-1.1)$ \\
\hline Blood pyruvate $\mathrm{mmol} / \mathrm{l}$ & 0.32 & 0.34 & 0.40 & 0.37 & 0.18 & 0.15 & $(0.04-0.11)$ \\
\hline Blood $\mathbf{L} / \mathbf{P}$ ratio & 55 & 38 & 14 & 10 & 13 & 15 & $(5.9-14.0)$ \\
\hline Blood alanine $\mathrm{mmol} / \mathrm{l}$ & 0.64 & 0.57 & 0.47 & 0.52 & 0.34 & 0.24 & $(0.18-0.37)$ \\
\hline Blood glycerol $\mathrm{mmol} / \mathrm{l}$ & 0.51 & 0.44 & 0.06 & 0.06 & 0.04 & 0.03 & $(0.05-0.09)$ \\
\hline Plasma NEFA mmol/l & 0.65 & 0.61 & 0.73 & 0.56 & 0.44 & 0.35 & $(0.43-1.00)$ \\
\hline NEFA/glycerol ratio & 1.3 & 1.4 & 12.2 & 9.3 & 11.0 & 11.7 & $(6.1-18.6)$ \\
\hline Blood OHB mmol/l & 0.11 & 0.09 & 0.05 & 0.03 & 0.04 & 0.03 & $(0.03-0.09)$ \\
\hline
\end{tabular}

Reference ranges for blood cyanide and thiocyanate concentrations were supplied by the Regional Laboratory for Toxicology, Dudley Road Hospital, Birmingham. Fasting hormone and metabolite reference values were obtained in 8 men (mean \pm s.d.), age $22 \pm 2$ years.

$\mathrm{OHB}=3$-hydroxybutyrate; NA = not available, ${ }^{*}$ non smokers; NEFA = non-esterified fatty acid. $\mathrm{L} / \mathrm{P}=$ lactate pyruvate.

encephalogram failed to show any cerebral activity. Three days after his admission formal brain death testing was undertaken. This failed to show any brain stem activity and ventilation was discontinued after both kidneys had been donated for transplantation.'

\section{Discussion}

The metabolic sequelae of cyanide poisoning are poorly documented in humans although lactic acidosis is recognized. ${ }^{2}$ The marked acidosis in our case was due to excess lactate produced by anaerobic metabolism of glucose. With the paralysis of mitochondrial respiration, glycolysis is enhanced by the Pasteur effect in which allosteric ATP and citrate inhibition of phosphofructokinase is lost $^{3}$ and reoxidation of cytoplasmic NADH formed by triose oxidation occurs in the conversion of pyruvate to lactate.

Altered hepatic lactate metabolism as well as increased lactate production by other tissues contributes to lactate accumulation. ${ }^{4}$ It is well recognized that hepatic lactate and pyruvate uptake are diminished in acidosis by an effect upon their transport which is pH-dependent. ${ }^{5}$ Increased hepatic intracellular $\mathrm{H}^{+}$ concentration also results in conversion of pyruvate to lactate by lactate dehydrogenase. ${ }^{6}$ Acidosis further impairs gluconeogenesis at the step between pyruvate and oxaloacetate 5 and cyanide poisoning would also inhibit this reaction by decreasing intramitochondrial
ATP concentrations. The liver thus becomes a net lactate producer. ${ }^{6}$ Impairment of gluconeogenesis in our case is supported by elevated concentrations of the other gluconeogenic precursors alanine and glycerol

Despite the severity of cyanide poisoning, near normal initial non-esterified fatty acid (NEFA) concentrations might suggest that NEFA utilization proceeded and the high normal initial concentrations of 3-hydroxybutyrate $(\mathrm{OHB})$ could indicate that NEFA activation to fatty acyl-CoA and intramitochondrial NEFA B-oxidation continued. However, OHB concentrations also depend upon peripheral utilization and this may have been impaired by lack of mitochondrial NAD ${ }^{+}$?

During the first 24 hours NEFA and glycerol concentrations did show suppression and their ratios returned to normal, suggesting a normal lipolytic rate, but only at insulin concentrations indicative of gross insulin resistance. ${ }^{8}$ Similarly, OHB concentrations were resistant to suppression by insulin. ${ }^{8}$ Insulin infusion appeared to have little effect upon glucose metabolism.

In summary we report a case of fatal cyanide poisoning. The metabolic complications were lactic acidosis, a known association ${ }^{2}$ but also a severe degree of insulin resistance in glucose, ketone and fatty acid metabolism. The correction of these metabolic abnormalities were refractory to the early detoxification of blood cyanide, intensive supportive therapy and insulin infusion. Extensive cellular damage occurred prior to onset of therapy highlighting the importance of preventative measures in occupational health. 


\section{References}

1. Brown, P.W.G., Buckles, J.A.C., Jain, A.B. \& McMaster, P. Successful cadaveric renal transplantation from a donor who died of cyanide poisoning. $\mathrm{Br}$ Med J 1987, 294: 1325.

2. Graham, D.L., Laman, D., Theodore, J. \& Robin, E. Acute cyanide poisoning complicated by lactic acidosis and pulmonary oedema. Arch Int Med 1977, 137: $1051-1055$.

3. Bloxham, D.P. \& Lardy, H.A. Phosphofructokinase. In: Boyer, P.D. (ed.) The Enzymes, volume 8. Academic Press, New York, 1973, pp. 239-278.

4. Cohen, R.D. \& Woods, H.F. Lactic acidosis revisited. Diabetes 1983, 32: 181-191.
5. Schwab, A.J., Bracht, A. \& Scholz, R. Transport of D-lactate in perfused rat liver. Eur J Biochem 1979, 102: 537-547.

6. Fine, A., Brosnan, J.T. \& Herzberg, G.R. Release of lactate by the liver in metabolic acidosis. Metabolism 1984 , 33: 393-396.

7. Sahlin, K. \& Katz, A. The content of NADH in rat skeletal muscle at rest and after cyanide poisoning. Biochem J 1986, 239: 245-248.

8. Hale, P.J., Wright, J.V. \& Nattrass, M. Differences in insulin sensitivity between normal men and women. Metabolism 1985, 34: 1133-1138. 